\title{
Research on the Influence of Higher Education on Economic Growth
}

\begin{abstract}
Ziqian Wang ${ }^{1, *}$
${ }^{1}$ Beijing Jiaotong University, Beijing, China

* Corresponding author: 18241126@bjtu.edu.cn

ABSTRACT

In the current society, the relationship between education and the economy is more and more inseparable. Under the dual pressure of economic development and the cultivation of high-level innovative talents, measuring the relationship between China's higher education and economic growth and making it better serve the socialist modernization construction is particularly important. Under this economic situation, the prerequisite and necessary condition to realize the new upgrading of China's economy are to realize the upgrading of China's higher education first to provide the society with talents with rich knowledge and high innovation ability.Based on the theory of human capital and economic growth-related theory, this paper reviews the relative literature on the relationship between economic growth and development of higher education and analyze the current situation about higher education in China from qualitative and quantitative perspectives through the methods like Granger causality test, the economic contribution rate and so on. The Granger causality test showed an obvious interactive relationship between higher education development and economic growth, and the degree of coordination between them showed a rising trend year by year. It was concluded that higher education and economic growth were mutually promoting: Economic development and investment in education will promote the development of education, which in turn will promote economic growth as well.
\end{abstract}

Keywords: higher education, economic growth.

\section{INTRODUCTION}

The transition from high-speed growth to highquality development is an important transformation that China has experienced since the reform and opening up of the past 40 years, based on the reality of both achievements and constraints. Moreover, developing higher education to promote the accumulation of effective human capital and enhance the ability of scientific and technological innovation is an important approach to realize this change. In the contemporary world of a knowledge-based economy, the level of education has become an increasingly important factor in improving the comprehensive national strength. The competition among countries in the comprehensive national strength has been transformed into the competition for talents. Countries also pay more attention to the role of education and talents in economic growth. China's productivity and education level are low. The talent situation can not meet the needs of international competition and industrial structure adjustment. How to change the population pressure into human resources is a major problem for our country.
Higher education has the function of knowledge creation and the characteristics of knowledge processing and knowledge dissemination, which is the link between economic development and talent training. To some extent, the innovation ability of a country is determined by the development level of higher education, which further affects the economic growth and development speed of a country. Therefore, it is a significant practical problem under the new background to measure the relationship between higher education and economic growth and solve the problem according to the analysis results.

The literature review is of great theoretical significance to enrich and develop the analytical framework of the research on the relationship between higher education and economic growth and to expand the research perspective. It is of great practical significance to objectively understand and evaluate whether the scale, structure, and layout of China's higher education are moderate, reasonable, and perfect, and to put forward targeted policy suggestions to promote the sustainable and healthy development of China's higher education 


\section{RESEARCH METHODOLOGY}

\subsection{Data collection and collation}

The data collected in this paper were mainly from three Chinese retrieval databases: CNKI, VIP, and Wanfang. After re-analysis, all the papers related to higher education and economic growth published in 1960-2021 were set as the literature period. After excluding the papers with poor relevance in academic research, such as book reviews, interviews, and news reports, on the basis of the initial literature collection, the paper was screened for the second time by multiple factors, such as source journal analysis, author unit analysis, supporting fund and platform analysis, academic analysis of paper titles, and paper citation frequency analysis. Finally, the academic research papers on the relationship between higher education and economic development with high academic, high relevance, and high citation frequency were extracted from the three major Chinese retrieval databases.From the quantitative visual analysis and preliminary statistical classification of relevant literature, the research on higher education and economic growth in China has mainly increased since 2004, decreased since 2018, and increased slightly since 2019 , then the study of this subject began to fade away.

The Author classified the topics of the paper. Overall, the relationship between higher education and economic growth was gradually deepening and diversified. The early research started from exploring the source of economic growth, so it focused on the theoretical analysis of the relationship between higher education and economic growth and the study of the contribution rate of higher education in economic growth. With the rise of human capital theory and new growth theory, the importance of education, especially higher education, to promote scientific and technological progress and accumulate human capital was widely recognized.

\subsection{Theoretical basis}

Theoretically, the realization of the economic function of higher education, or the impact of higher education on economic development, can be analyzed under the supply framework of neoclassical economics. Under this framework, economic growth is driven by capital factors, labor factors, technological innovation and effective institutions.Among them, the capital element includes both material capital and human capital. Compared with physical capital, human capital plays a more powerful role.Moreover, among all the driving factors mentioned above, according to the human capital theory, economic development mainly depends on the accumulation of human capital, rather than on the abundance of natural resources and the amount of material capital, this is because human capital, as a type of capital embodied in workers, is the sum of the values of workers' knowledge, technology, ability and health. Only by improving people's comprehensive quality can a more efficient input-output ratio be brought about. It is obvious that higher education shoulders the heavy responsibility of training senior talents. See Fig.1.

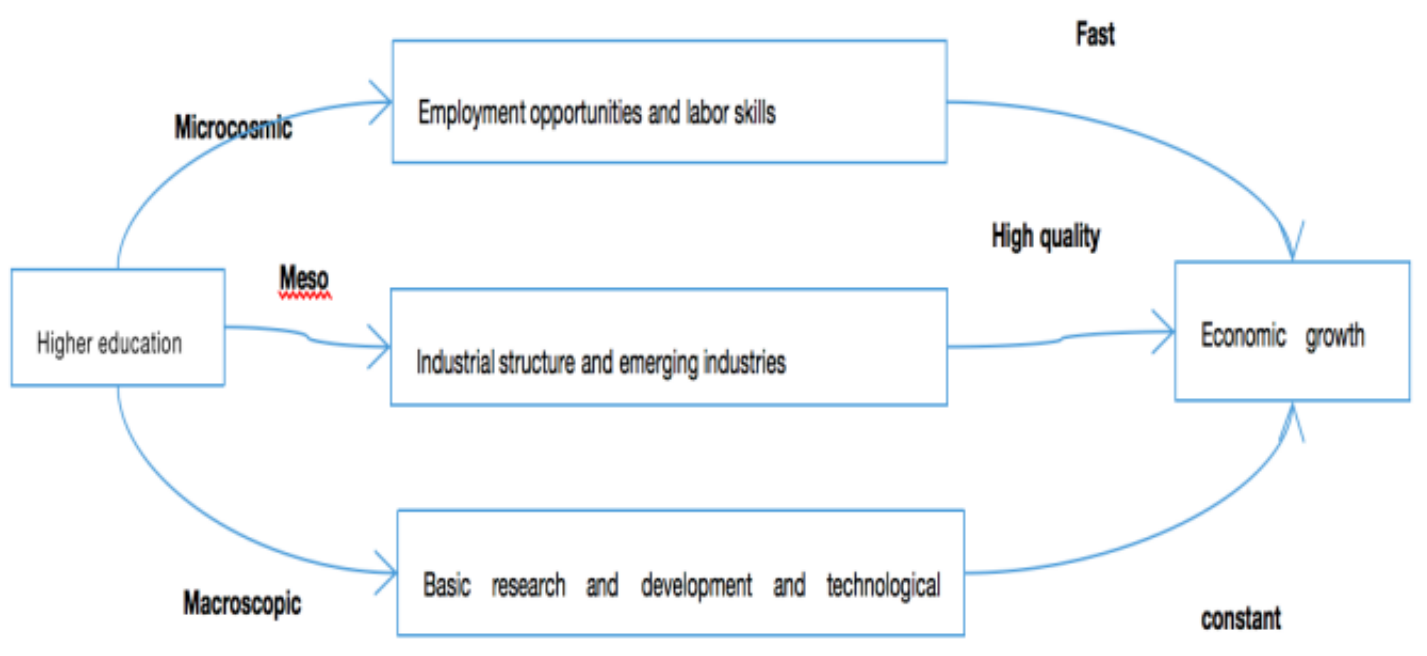

Fig. 1. The operation mechanism of economic function of higher education.

\section{LITERATURE REVIEW}

\subsection{A study on the contribution rate of higher education to the economy}

The development history of economic growth theory is also the evolution history of the study of the relationship between education and economic growth. From the early classical literature, economists only used capital as the only factor of economic growth to the labor force factor. The relationship between education and 
economic growth was not obvious. With the vigorous development of human capital theory and new growth theory, education, especially as the highest level of education, has become widely known for promoting economic growth.

The empirical study of the relationship between higher education and economic growth originated from the measurement of the contribution rate of higher education in economic growth, In this measure and measurement, the methods used by scholars at home and abroad mainly include residual value analysis (or educational rate of return), factor analysis, present value discount algorithm, and labor simplification law and so on. Schultz[1] initiated the study of the contribution of education to economic growth using quantitative analysis. He found that the average annual return on U.S. investment in education at all levels was 17 percent, the contribution rate of higher education to economic growth reached $32.49 \%$ by residual value method. Denison[2] decomposed the factors that affect economic growth. From the 1920 s to the 1950 s, education contributed a fifth of American economic growth. Maddisoon [3] used Denison's method to measure the contribution rate of higher education to economic growth in western countries after World War I. The results showed that the contribution rate of higher education had increased significantly after the 1970s. Joegenson found that the contribution of human capital to American economic growth in 1948 1986 reached 26\% through economic growth accounting. This paper studied the relationship between different levels of education and a country' $s$ economic level, and found that higher education only contributed more to the economic growth of developed countries, and the economic growth of developing countries had a greater relationship with primary or secondary education. An upside-down U relationship between educational years and economic growth was proposed, while the peak value of educational years to economic growth was 7.5 years. That is, the average number of years of education in a country exceeding this peak might have a negative impact on economic growth. Menon and Card have analyzed the relationship between educational investment and economic growth through quantitative methods, but the former conclusion was that education was the cause, the latter was the opposite. Stephan measured the rate of return on higher education in the United States, the results show that different economic levels have different rates of return.

Yingzhang Zhou et al. explored the contribution of education to national income from 1952 to 1998 after the founding of New China through the comprehensive application of the co-integration test and other methods, and the result was 0.976. Hai Jun Huang et al. [4] based on the panel data collected from 29 provinces and cities from 1996 to 2009, it has been found that the annual contribution rate of graduate education to GDP growth was about $4 \%$, which had a relatively obvious positive effect. Ling Li adopted the static index system to calculate the contribution of China's education investment to economic growth. The contribution rate of education investment to economic growth was verified again by dynamic regression model; Yajun Yang, Li Hongtian [5] constructed the model of production function construction, selected indicators related to the educational quality of workers and economic growth in Jiangsu Province, and made economic calculation and analysis on the problem of contribution rate. The analysis results showed that education and economy in Jiangsu Province were closely related, which could better promote the development of the regional economy, but the contribution rate of higher education to economic growth was generally low. It was an important subject to attach importance to the relationship between higher education and economic growth in Jiangsu Province in the future.

Tianping Yang and Zhaoxin Liu [6] also built models based on Cobb-Douglas production function. In conjunction with the comprehensive index of education, the contribution rate of higher education and economic growth was measured. It turned out that since 2001, the contribution rate of higher education to economic growth was 3.62 and the statistic of this index was only equivalent to the level of western developed countries in 1970s.

Based on the data from 2000-2012, Fengli Lin, Xicang Zhao and Yahui Chen[7] studied the contribution rate of higher education to economic growth in Jilin Province. It was found that the contribution rate of higher education in Jilin Province to Jilin economic growth was low, even not reaching the national average. Wang Xiaoting and Cui Yuping[8] estimated and measured the contribution rate of education to economic growth in Jiangsu Province in the past 20 years by combining two methods, Kogelgras production function and transcend logarithmic production function, compared and analyzed from multiple perspectives, and analyzed the advantages and disadvantages and rationality of different methods.

In addition to the research on the contribution rate of higher education to economic growth, domestic scholars have gradually turned to carry out a series of qualitative or quantitative studies on the relationship between higher education and economic growth.

\subsection{Research on the Interaction and Coordination between Higher Education and Economic Growth}

Bin Chen made a simple sorting out and general review of the development and evolution of the relationship between the two. Yiying $\mathrm{Wu}$ expounded the relationship between universality and particularity of higher education and economy through dialectical analysis and the specific manifestation of the relationship. 
Hongtao Mao and Dan Ma[9] did not analyze the relationship between higher education and economic growth from a qualitative point of view but directly from a quantitative point of view, and discussed whether there was a quantitative relationship between the two for the first time. After straightening out the relationship between financial input and economy, Hui Wu et al.[10] put aside the input in human resources and other aspect of higher education, after straightening out the relationship between fiscal input and economy, explored the internal mechanism of the two through the application of many measurement methods, and obtained the Spearman coefficient of 0.979 , indicating that there was a significant positive relationship between the two. When Wenyan Liang[11] combed the previous studies, she thought that the quality of education played a key role in the sustainable growth of the national economy.

Some scholars believed that the coordination between higher education and the economy was very weak or even irrelevant. Yingchun Zhu et al. [12] used Granger causality test to quantify the interaction between higher education and economic growth. The results showed that there was no causality. Junlan Cai[13] selected 9 indicators from the data of Guangdong Province and Zhejiang Province from 1978 to 2009, and carried out trend-eliminating treatment on time series variables. Through the research on relevant data of Guangdong and Zhejiang, he obtained the fact that higher education fluctuated periodically; Shukuan Zhao[14] building a relationship between higher education and economic growth, on the basis of a conceptual model of the integrated use of cointegration, impulsed response function and variance decomposition, and many other tools, to analyze the relationship in a long period of time, it was concluded that the higher education funds and manpower into a $1 \%$ increase, would cause GDP increased by $0.3 \%$ and $1.2 \%$ respectively. Shuqing Xie and Jing Li[15] set up the higher education-economic growth conforming system coordination model. The analysis showed that after 1999, the degree of coordination between higher education and economic growth was significantly improved, and the two develop in coordination. However, the system order degree of Xinjiang' $\mathrm{s}$ economic growth subsystem was low. Jianzhong Qu[16] used the system coordination degree evaluation model to calculate the coordination degree between higher education and economic development in China. The conclusion was that the development of higher education and economic development in China generally presented a very weak coordination state.

Some scholars believed that the current disharmony between the two had been slowly decreasing or had been basically coordinated. Zhidan Tang et al.[17] classified the 31 provinces and municipalities in China into 5 gradients in terms of higher education development and economic growth. At the same time, this paper analyzes the basic situation of these two aspects in Liaoning
Province. The results showed that the economy and higher education in Liaoning Province had a growing trend, and the direction and pace of development and change were basically the same, and it was relatively balanced. Shuangbo Yan[18] constructed the coupling coordination degree model between education and economic development based on the coupling theory and conducted empirical research and analysis on the coupling degree and coupling coordination degree of the two. It was found that with the development of economy and society, the degree of coupling coordination between the two showed a good trend of continuous increase. Jinhui Dai[19] analyzed the related indexes of higher education development and science and technology development in 2015-2017, and studied the degree of coordination between the two systems. The results showed that the degree of coordination between the two was increasing year by year.

Zichen Wang used Granger causality test to test whether there was a statistical causality between higher education and economic growth. And the outcome is as follows. See Table. 2 and Table. 3

Table. 1. The results of Granger causality test in the stable development period of higher education

\begin{tabular}{|c|c|c|}
\hline Null Hypothesis & F-Statistic & Probability \\
\hline $\begin{array}{c}\text { LNGDP does not Granger } \\
\text { Cause LNEDU }\end{array}$ & 7.36974 & 0.00558 \\
\hline $\begin{array}{c}\text { LNGDP does not Granger } \\
\text { Cause LNGDP }\end{array}$ & 1.98550 & 0.17467 \\
\hline
\end{tabular}

Table. 2. Granger causality test in the rapid expansion of higher education

\begin{tabular}{|c|c|c|}
\hline Null Hypothesis & F-Statistic & Probability \\
\hline $\begin{array}{c}\text { LNGDP does not Granger } \\
\text { Cause LNEDU }\end{array}$ & 1.69415 & 0.24351 \\
\hline $\begin{array}{c}\text { LNGDP does not Granger } \\
\text { Cause LNGDP }\end{array}$ & 4.82186 & 0.04227 \\
\hline
\end{tabular}

In general, comparing the causality test results of two groups of time series data in two periods, we can see that with the expansion of the scale of higher education, the time lag of interaction between the two is decreasing, the interaction cycle is shortened, and the interaction is more frequent. At the same time, the influence of higher education scale on economic growth from the stable development period is not obvious to the rapid expansion period is the Granger reason, indicating that the expansion of higher education from the effect of promoting higher education and economy. The interaction of economic growth has played the role of the engine of scientific and technological progress of higher education and the cradle of human capital. 


\subsection{Higher education hierarchy and economic growth}

Maoyuan Pan believed that the industrial structure of the national economy was the main factor restricting the discipline structure of higher education. Therefore, in order to evaluate the rationality of higher education structure, it is necessary to see whether it matches the demand of industrial structure for talents. Tingting Zhaoanalyzed the course of discipline structure adjustment of British higher education, and proposed that since the 1970s, the establishment of a large number of polytechnical colleges has reversed the problem of discipline structure imbalance in the UK, and made it more adaptable to the social economy. Fang Li analyzed how the higher education structure adapted to the industrial structure adjustment from the perspective of the change of human resource demand in China. Zhanjun Wang et al. [20]made a comparative analysis of the structure of postgraduate disciplines in China, the United States and Japan. It was suggested that the structure should be optimized according to social needs. Houfeng Chen[21] analyzed the correlation between China's higher education structure and economic structure since enrollment expansion. Conclude that the types and hierarchical structure of higher education should actively adapt to the industrial structure and employment structure, and the expansion plan of the scale of higher education should take the employment capacity and the number of employment positions as important basis. Zheng $\mathrm{Fu}[22]$ used principal component analysis and clustered analysis to analyze the coordination between regional structure, hierarchical structure and formal structure of higher education and economic development. Jingming Chi et al. [23]conducted principal component analysis and correlation analysis on the hierarchy structure of higher education and economic development, and the results showed that the hierarchy structure of higher education in China from 1998 to 2007 basically met the needs of economic development, and the two fit well. Zhanguo Li[24] analyzed the interaction between the subject structure and industrial structure of American higher education in different periods. It was suggested that the increasingly frequent interaction between higher education and the economy in the United States depended on the establishment and development of land grant colleges to a great extent.

With the research on the relationship between regional higher education and economic development becoming a hot topic, the research on the relationship between regional higher education structure and economy has gradually increased in recent years. Wei Ge et al. found that the structural contradiction between Baoding' s industrial structure and employment structure was prominent. Xuebin Qiao et al. [25] used grey correlation analysis to measure the structure of higher education in Jiangsu Province and the three industrial employment structure of graduates. At the same time, the Moore value method was used to reflect the changes of higher education structure and industrial structure. The results showed that the time lag between the two was long. Yanling Wang[26] used the Granger causality test to measure the interaction between higher education and industrial structure in Anhui Province in 1992-2010. The results showed a long-term equilibrium relationship, but there was no causal relationship, and the interaction was weak.

\subsection{Regional higher education and economic growth}

The relationship between the layout of higher education and economic growth was mainly reflected in the exploration of the relationship between higher education and economic growth from the regional perspective. Caffry J[27] discussed the relationship between higher education and regional economy from the employment effect of higher education. Bluestone believed that graduates with higher education would receive relatively more remuneration and pay more taxes, and higher education could increase regional tax revenue and thus promote economic growth. Batterbury found that higher education was the engine of regional economic development. Yunhua $\mathrm{Gu}$ analyzed the characteristics of higher education development in different regions under the background of unbalanced development and put forward some countermeasures and suggestions to promote the coordinated development of higher education and the regional economy. Jian Liu et al . put forward that talent training and transformation of scientific and technological achievements were the main ways for higher education to promote regional economic growth. Zhenchao Zhou et al. [28]pointed out that the unbalanced development of the regional economy in China required regional higher education to be based on region and adapt to regional economic development. Zhenzhu Zhang[29] put forward that higher education was the driving force of regional economic growth and used grade difference to evaluate the coordination between higher education and the regional economy. The results showed that there was no coordination between provinces and cities. Zhipan $\mathrm{Wu}[30]$ pointed out that with the development of the economy and the change of economic structure, colleges and universities spread out from the central city. Yimin Yang[31] used the improved grade difference method to measure the coordination degree between the scale of higher education and regional economic growth. The results showed that the coordination degree in the central region was high. Congli Yao took the ratio of higher education scale to economic scale as the index to measure the synchronization of higher education development speed and economic development and found that the development speed of higher education scale in the western region was slightly ahead of the development 
speed of the economic scale.The structure of higher education in the western region was mainly oriented to basic education and did not directly point to the regional economy. Kaihong Zhang[32] used Cobb Douglas production function to measure the contribution rate of higher education to economic growth in six central provinces. The results showed that the difference was obvious. Yingchun $\mathrm{Zhu[33]}$ calculated that the contribution rate of higher education to regional economic growth showed a decreasing trend from east to west, and put forward that higher education was an important factor affecting the widening gap of regional economic development in China. Yanhong Fang proposed that higher education level represented the level of the regional economy and should pay attention to the degree of coordination and interaction between the two. Guochun Zhao and Yong Liang[34] found that the synergy between higher education and local economic development in minority areas was decreasing year by year. Binbin $\mathrm{Li}$ et al. [35]took the five northwest provinces (districts) as an example to analyze the relationship between the scale of higher education and economic growth. It was found that the scale of higher education in this region was lower than the economic growth rate. Except for Shaanxi Province, the fluctuation of education development in the other four provinces was more obvious, and the effect of higher education policy was more significant. Desheng Lai, Qi Wang and Danxi Shi[36] used the data from 2007 to 2012 to analyze the impact of higher education quality differences on regional innovation and believed that under the same other conditions, higher education quality differences should be moderate for those regions with moderate differences had the most significant impact on innovation. Zhaohui Jiangbelieved that the distribution of higher education resources in China presented an unbalanced situation between the east and the west. Most of the highquality educational resources were concentrated in the eastern coastal areas, while the resources in the central and western regions were deficient and could not meet the development requirements of the region at the present stage. This excessive concentration of resource investment had affected the overall ecological system construction of higher education. When Juan Nie and Shibo Xin[37] studied the differences in higher education quality among different provinces, they mentioned that the overall level of higher education quality in China was relatively backward. There were significant differences in higher education quality among colleges and universities in different provinces. When studying the quality gap of higher education, Bo Liu found that the opportunity inequality in the quality gap of higher education was far greater than that of higher education. Although the gap in higher education had narrowed in terms of regions, the opportunities to enter key universities have had gradually solidified.

\subsection{The relationship between the quality and scale of higher education and economic growth}

Wenbo Cai and Lu Cheng[38] made a detailed analysis of economic growth and education scale in Xinjiang Province and believed that there was a dynamic equilibrium relationship between the scale of higher education and the economic growth in the region. From the long-term equilibrium relationship, expanding the scale of education had a positive impact on the economic growth of Xinjiang Province. Yonghong Zhou and Yang Xiong[39] through the establishment of the education investment model found that improving the quality and scale of higher education would have a positive effect on China's current economic development, and the improvement of the former had a more significant positive effect on economic development. Laijun Luo et al. [40]constructed the growth model of education quality and economy and believed that the expansion of education scale could promote the increase of economic growth rate.

There are also scholars who believed that the scale of higher education in some areas had a limited impact on economic development. Yang Yimin [41] used the method of randomized trial to explore the effect of higher education scale on per capita GDP in different regions, and believed that the effect of higher education scale on per capita GDP was not significant in the eastern and western regions of China.It should also be realized that there was still a big gap between the development of China' s higher education quality and that of developed countries. Junping Qiu, Song Bo, Chuanyi Wang[42] all believe that higher education has a significant gap with developed countries in terms of talent cultivation quality, influence transformation of high-level scientific research achievements and infrastructure.

\subsection{The relationship between investment of scientific research funds in higher education and economic growth}

Foreign scholars' research on S\&T input and economic growth started earlier and the content was relatively rich. The material basis of scientific research activities is scientific research input, the improvement of total factor productivity depends on scientific research progress, and the transformation and upgrading of industries and the high-quality development of economy all depend on knowledge accumulation and technological progress. Romer et al. [43]believed that scientific research and innovation activities needed the demonstration and guarantee role of financial investment in science and technology so as to achieve long-term sustainable economic growth. Freire-Seren pointed out that whether scientific research investment can promote stable economic growth and whether scientific research investment can be converted into real wealth increase 
were two indicators to measure the rationality of scientific research investment. Seck[44] processed the data of fifty developing countries with the economic model in econometrics, and the empirical results showed that the positive effect of scientific research innovation on economic growth was realized through the way of knowledge spillover. Kamyab found that knowledge could not spill out spontaneously, which was different from the classical theory of new economic growth. As the main way of knowledge spill, scientific research innovation had an impact on economic growth.

Domestic research started relatively late, but domestic scholars in this field of research results were quite sufficient. In terms of research scope, there were both regional and national ones. In data processing, time series or panel series data were mostly used, covering common econometrics research methods.

Liyu Zhao and Ping Shi found that there was a longterm equilibrium relationship between China's fiscal investment in scientific research and economic growth in the co-integration test, and the former had a significant positive correlation with the latter. On the basis of the theoretical study on R\&D investment and its spillover effect, Zuchang Zhong made an empirical study by using the spatial panel measurement method, and the results showed that there were significant differences in R\&D investment and its spillover effect between the eastern and western regions. Yang Gao and Qizhi Cheng used co-integration test, Granger causality test, unit root test, and other econometric methods to study the relationship between scientific research input and economic growth in Shandong Province, and the empirical results showed that abundant scientific research input did not play a promoting role in increasing regional GDP, this study studied the low conversion rate of scientific research results, excessive government intervention and the quality of researchers, and put forward relevant policy suggestions from the perspective of improving the business environment. Youzhi Zhang tried to establish a smoothing transformation regression model to focus on the correlation between the two. The research showed that only when the relationship between the fiscal research expenditure and GDP exceeded the ratio of $0.8 \%$ could the fiscal research expenditure have a significant positive effect on economic growth.

Wenbo Cai and Lu Cheng, on the basis of constructing the VAR model of economic growth and investment in higher education in western China, used the Johansen co-integration test, Granger causality test, impulse response function, variance decomposition, and other empirical analysis methods to explore the dynamic interactive relationship between economic growth and investment in higher education in western China. The results showed that there was a long-term dynamic equilibrium relationship between the economic growth and the investment in higher education in western China, and every $1 \%$ increase in the investment in higher education can cause the economic growth in western China to reach $1.659 \%$. At the same time, there was a two-way Granger causality between them, and they had a positive effect on each other.

Dan $\mathrm{Wu}$ and Shidong Wang discussed Chinese government investment in science and technology and economic growth by means of regression analysis and co-integration test, and the results showed that the average contribution of the former to the latter was as high as $13.2 \%$, and there was a significant long-term stable positive correlation between the two. Shi Chen and Liang Wang discussed the different influences of scientific research funding from different sources on economic growth in the process of dynamic change through the research model, and through the horizontal comparison with the research input and output of developed countries, the problems worth attention in the research input were explained. Weibing Tang and Yuanhai Fu made an empirical study and tried to use the state-space model. The results showed that the investment in scientific research promoted the development of economic intensification, and the restrictive effect was often from the spillover of foreign technology.

\section{DISCUSSION OF EXISTING LITERATURE}

By reviewing and summarizing the scholars' research literature on the relationship between higher education and economic growth, it could be seen that there are several obvious characteristics.

First of all, qualitative research is the main research method of this research content, the quantitative research results are less, and the quantitative research method is more traditional and single. Second, scholars mainly focus on the relationship between higher education level, higher education scale, higher education investment and economic growth. The content of the research is onesided and cannot reflect the interaction between the whole higher education and economic growth. Third, the research method is more traditional, and the research method is relatively single, which makes the analysis results lack hierarchy and contrast.

It can be seen that the existing research has experienced a process of development for the measurement of the degree of coordination between higher education and economic growth. However, there are still some shortcomings in reflecting the scientific and reasonable degree of coordination.

From the research on the relationship between higher education scale and economic growth, the discussion of the relationship between higher education structure and economic growth has gradually become a hot spot in recent years. From the perspective of research methods, from the initial speculative and qualitative description of 
higher education and economic growth to quantitative analysis, the use of improved production function method, econometric method, system science method, data envelopment analysis, and another multidimensional measurement of higher education and economic growth.

In the study of the relationship between higher education structure and economic growth, some studies have generally accepted the restrictive effect of industrial structure on higher education structure, but there are few studies on the quantitative analysis of higher education structure and industrial structure directly. Most studies start with employment, introduce employment structure as a bridge between the two, and draw the conclusion that the structure of higher education is unreasonable by studying the relationship between them. Its advantage is that it can better reflect the labor flow brought by industrial structure adjustment and its influence on higher education structure. The disadvantage is that it can not directly reflect the relationship between the structural change of higher education and the upgrading and transformation of industrial structure from the perspective of higher education structure, and lack of research on the degree of correlation between the two.

In recent years, the study of the relationship between higher education structure and economic growth has involved a regional level. Theoretical analysis or descriptive statistics on the relationship between regional higher education structure and industrial structure are used to determine whether they are suitable or Granger causality test or grey correlation is used to analyze one aspect of higher education structure and industrial structure. However, through combing the existing literature on the relationship between the two, it could be found that qualitative analysis is the majority, and the research of quantitative analysis is often limited to a certain level of structure, such as hierarchical structure or branch structure - lack of quantitative research on the relationship between higher education structure and economic growth.

Through sorting out the existing literature on the quality of higher education, it was found that the research suggestions in this aspect were superficial and partial to idealization, which is difficult to implement in practice, only theoretically explaining some measures can improve the quality of higher education, but whether and to what extent they could improve remains to be tested. And the research process did not carry out effective field research, did not fully consider the diversity of universities. Not all universities are suitable for the development of research-oriented universities. The students trained by colleges and universities can have the skills to serve the society, which is only necessary for them to have "specificity" . In addition, the quality of students' learning was also not included in the study, so it is easy to bias the results when the education gap between regions is measured by only part of the factors. Apart from that, from the quantitative point of view, there were few articles, which aspects should be paid attention to improve the quality of higher education and which aspects can be appropriately slowed down were not clearly stated. Although there were a few studies from the quantitative point of view, most of them analyzed the similarities and differences in the balanced degree or development level of higher education between regions, and the selection of indicators in the quantitative analysis was lack of comprehensiveness. In addition, it was difficult to control the influence of irrelevant factors in the process of regression, which led to errors in measuring the effect of higher education quality on regional economy.

In terms of research contents and methods, most of the researches on scientific research investment in higher education focused on finding problems from the perspective of research activities and economic growth in universities. Most of the policy suggestions were focused on the cooperation between production, education, and research and the guarantee of scientific research funds in universities. The comprehensive analysis of the input, output process and results of scientific research funds in universities was lacking, and the discussion on the enhancement or weakening effect of other factors in the influence process was ignored, and the "black box" of the effect of university research funds on economic growth was still unclear. In the empirical research, the general methods of econometrics research have been tried to use. However, in the process of concrete empirical analysis, the investment of scientific research funds is centered.

As for the discussion of economic growth, some scholars should discuss the development of the economy, but in the literature can only see the growth of GDP numbers, I think development and growth are different. Growth is only an increase in quantity, and economic development should also include the coordination of social systems, the improvement of quality of life, and so on. At the same time, most researchers put some educational and economic indicators into the model analysis, but the economic factors are very many, just look at the fluctuation of the two at the same time to build the relationship between the two, the calculation of the contribution rate may not be very accurate.

In future research, it is undeniable that the contribution rate of higher education to the economy is relatively large and direct, but what impact and how much impact are worth exploring in depth. And it is feasible to choose more indicators that represent economic development to analyze. Most of the studies now focus on the comparison between provinces, and the comparison between the western, developed and backward regions of the Middle East, which lacks the 
coordination analysis within the provinces, so we can also research in this area.

\section{CONCLUSION}

This paper mainly studies the interactive relationship between higher education and economic growth in China. First of all, it reviews the relevant literature on the relationship between higher education and economic growth in the past, studies it, and summarizes its research experience and shortcomings. From the quantitative point of view, most scholars calculate the contribution rate of education to the economy and then explain the important role of education. In addition, most of the research starts from the relationship between macroscopic level and social system. The theory has a macroscopic guiding function, but it is difficult to operate in the concrete economic development process.

In the policy recommendations, Xia Chen and Bin Liu mentioned the need to continue to increase financial investment in higher education. From the conclusion of this essay, it is concluded that increasing financial investment in higher education can positively affect economic growth in the current period, so it is necessary for China to continue to increase financial input to higher education. In this way, the accumulation speed of human capital in China can be improved, the reserve of talents can be increased, and higher education demand can be met. And it was concluded that higher education tuition prices should be reasonably set according to national conditions. The conclusion shows that the current investment structure of higher education in China is on the left of the U-shaped peak, and increasing the proportion of household investment can effectively stimulate the growth of the economy.

Chuanjian Zhang suggested that the productionuniversity-research-application and research of knowledge technology should enhance regional economic growth. Production-university-researchapplication is the link between university knowledge production, scientific and technological innovation, and various subjects in the region, which is related to whether higher education can promote regional economic growth. Hudson compared universities to an open system when analyzing their impact on regional economic growth. In this system, the association between the university and the region is generated, and communication will have an impact on regional economic growth. The formation of human capital and the promotion of technological innovation to regional economic growth must take Production-university-research-application as its realization must condition.

The results show that the role of higher education is related to the level of economic development. The economic level restricts the development of higher education. To coordinate the important content to realize the comprehensive and coordinated development of social economy and implement the scientific development concept.

\section{REFERENCES}

[1] Schultz T.W. Investment in Human capital. American Economic Review. 51,1-17(1961)

[2] Denison E.F. Trends in American Economic Growth, (1985)

[3] Maddison, Angus. A long-run Perspective on Saving. Scandinavian Journal of Economics. 94(02),181196(1992)

[4] Haijun Huang.Research on the coordination between regional higher education and economic growth level in China. Journal of Education of Renmin University of China. 04,56-66(2011)

[5] Yajun Yang, Hongtian Li. Estimation and Analysis of Contribution Rate of Higher Education to Economic Growth in Jiangsu Province. The research on education.07,57-59(2016)

[6] Tianping Yang, Zhaoxin Liu.Higher Education in Zhejiang Province in the Process of Modernization: Problems and Countermeasures. Journal of Zhejiang Normal University.02,91-93(2015)

[7] Fengli Lin, Xicang Zhao and Yahui Chen.Research on the Contribution Rate of Higher Education to Economic Growth in Jilin Province.03,87-89(2015)

[8] Xiaoting Wang, Yuping Cui. Comparison of estimation methods of contribution rate of education to economic growthl. Statistics and Decision Making. 19,33-36(2015)

[9] Hongtao Mao, Dan Ma. Econometric analysis of the relationship between the development of higher education and economic growth. Science of finance and economics. 01(2004)

[10]Hui Wu, Zhixin Liu. Current situation and international comparison of financing of higher education in China. Journal of Shaanxi Normal University. 01,165-168(2010)

[11]Wenyan Liang, Yipeng Tang. A review of the research on education quality and national economic growth--and the enlightenment of China's education development under the background of "middle income trap". 09(05),58-59(2013)

[12]Yingchun Zhu, Dapeng Wang. An empirical study on the development of higher education and economic growth in China. Journal of Southwest Jiaotong University. 06(2009) 
[13]Junlan Cai. An Analysis of the Cycle Fluctuation of Higher Education in China: Descriptive Facts (1977-2009). 09,69-72(2011)

[14]Shukuan Zhao. Theoretical model and empirical study on the relationship between investment in higher education and economic growth. Higher Education Studies in China. 09(2011)

[15] Shuqing Xie, Jing Li. An empirical analysis on the coordination of the complex system of higher education and economic growth -- taking Xinjiang as an example. Xinjiang Social Sciences. 04(2013)

[16]Jianzhong Qu. Quantitative evaluation of the coordination between higher education and economic development in China. Hunan Social Sciences.01(2013)

[17]Zhidan Tang.An Empirical Study on the Development of Higher Education and Regional Economic Growth -- Taking Liaoning Province as an Example. Modern Educational Management. $\mathbf{0 3}(2010)$

[18] Shuangbo Yan. Research on the degree of coupling coordination between education and economic development in China. Education comments.01(2015)

[19]Jinhui Dai.Analysis on the coordination between the development level of higher education and the development level of science and technology. Statistics and Decision Making.01(2017)

[20]Zhanjun Wang. Comparison and Enlightenment of Discipline Structure of Graduate Education in China, America and Japan. Higher Education in China.Z2(2005)

[21]Houfeng Chen. Correlation analysis of economic structure and higher education structure in China since enrollment expansion. Research on higher engineering education. 01(2007)

[22]Zheng Fu. Analysis on the coordination between the structure of higher education and economic development. 02(2008)

[23] Jingming Chi. An empirical study on the relationship between the hierarchy structure of higher education and economic development. Education and Economics. 01,1-7(2010)

[24]Zhanguo Li, Renye Xie. Study on the interactive relationship between disciplinary structure and industrial structure in American universities. Higher Education Studies in China. 07,46-49(2011)

[25]Xuebin Qiao, Wenfan Yao, Haibin Zhao. Interaction and Covariation: A Study on the Correlation between Higher Education Structure, Graduate
Employment Structure and Industrial Structure. Journal of Southeast University. 04,122-126(2013)

[26] Yanling Wang. Study on the interaction between the development of regional higher education and the optimization and upgrading of industrial structure. Statistical observation. 02,107-109(2013)

[27]Caffry J, Isaacs H. Estimating the impacts of a College or University on the Local Economy.(1971)

[28]Zhenchao Zhou, Xiuju Tian. Reflections on the development of regional higher education. Higher Education Studies in China. 01,69-70(2002)

[29]Zhenzhu Zhang.Research on the interactive development of higher education and region. Research on Educational Development. 09,3944(2003)

[30]Zhipan Wu. Higher Education and Regional Development: An Investigation from the Perspective of Capital Education. Peking University Educational Review. 04,68-77(2013)

[31] Yimin Yang. Empirical analysis of regional higher education scale and economic development. Jiangsu higher education. 03,35-38(2006)

[32]Kaihong Zhang. Comparative study on the contribution rate of higher education to economic growth in six provinces in central China. Statistics and Decision Making. 17,84-86(2018)

[33] Yingchun Zhu, Zhigang Zhou, Dapeng Wang. An empirical study on the contribution of higher education to regional economic growth. Statistics and Decision Making. 02,88-90(2009)

[34]Guochun Zhao, Yong Liang. Research on the synergy between higher education and economic development in minority areas. Higher Education Studies in China. 05(2014)

[35]Binbin Li, Xiaoping Yang. Research on the correlation between the scale of higher education and economic growth -- based on the analysis after the expansion of colleges and universities in five provinces (regions) of northwest China. Journal of the National Institute of Educational Administration. 01(2015)

[36]Desheng Lai, Qi Wang, Danxi Shi. Quality difference of higher education and regional innovation. Education research. 36(02)(2015)

[37]Juan Nie and Shibo Xin. Differentiation of China's higher education quality and its effect on regional economic growth. China Soft Science. 11(2018)

[38] Wenbo Cai and Lu Cheng. Empirical analysis of the relationship between economic growth and higher 
education scale in Xinjiang based on VAR model. Higher Education Research in Heilongjiang Province. 12(2015)

[39] Yonghong Zhou, Xiong Yang.The Impact of Higher Education Quality on China's Economic Development: An Empirical Study Based on Provincial Panel Data. Journal of hubei university. 40(04)(2013)

[40]Laijun Luo.Endogenous Path Analysis of Influence of Education Scale and Quality on Economic Growth in China. Economic theory and economic management. 01(2009)

[41] Yimin Yang. Empirical analysis on the relationship between regional higher education scale and economic development. Jiangsu higher education. 03(2006)

[42]Junping Qiu, Bo Song, Chuanyi Wang. A Comparative Study of Higher Education Quality Development Index at Home and Awide. Education and Economics. 04(2019)

[43]Romer P M. Endogenous Technological Change. Nber Working Papers. 98(98), 71-102(1990)

[44]Seck. A International technology diffusion and economic growth:Explaining the spillover benefits to developing countries.Structural Change\&Economic Dynamics. 23(4),437451(2012) 